\title{
DISTRIBUTED SYSTEM APPROACH TO EXPERIMENT REGIONAL COMPETITIVENESS
}

\author{
Mhamed Itmi ${ }^{1}$ and Abdelkhalak El Hami ${ }^{2}$ \\ ${ }^{1}$ LITIS Laboratory, INSA Rouen Normandy, \\ University of Rouen Normandy. France \\ ${ }^{2}$ LMN Laboratory, INSA Rouen Normandy, \\ University of Rouen Normandy. France
}

\begin{abstract}
This paper highlights a work under development on a regional competitiveness project. We report on a multi-lateral, multi-scale perspective for building cooperative relationships that enhance competitiveness Regionally. The approach mimics a System of Systems methodology whereby entity relationships are captured and defined along several dimensions involving multiple constituents and multiple domain concerns. We build a serious game that is a distributed business simulator to approach the prototyping of this crossroads between supply chain management, geographical economics and information systems.
\end{abstract}

\section{KEYWORDS}

Adaptive systems, economic geography, multi agent systems, serious game, system of systems, supply chain management.

\section{INTRODUCTION}

In order to optimize the goods flows along the Seine River in France and to promote the territories, we need to find solutions to the current lack of quantified data but also the knowledge on the stakeholders' practices of the supply chain. In another hand a territory can be observed such as an autonomous system [1] that interacts with other territories with respect to some rules. An approach through systems of systems will be considered and used such as a serious game [2].

Some territories can differentiate themselves through a successful organization in spite of a good transport network. Logistics, thanks to infrastructure and organization, is connected to the spatial organization of the supply and distribution chain as expressed by [3]. The logistics performance is on the base of the territories competitiveness by the effect of the mutual interactions between logistics and territory. We need to prove that logistic performance boosts the territories competitiveness. To do it, we can choice the Seine axis territory because we have politicians who want to revitalize the collaboration between the economic actors of Paris, Rouen and Le Havre for the same aim: the improvement of the territory competitiveness and its sub-territories.

Our approach concerns the territorial competitiveness through the infrastructures development in particular of transport/logistics. In France and Europe, the extension of freight transportation networks will be limited in the near future due to important investments in their development

David C. Wyld et al. (Eds) : AIAPP, CRIS, CoSIT, SIGL, SEC - 2018

pp. 103-109, 2018. @ CS \& IT-CSCP 2018

DOI : $10.5121 /$ csit.2018.80409 
these last years. In socio-economics of transport, infrastructures and associated services are close. Indeed, the analysis of infrastructures allows obtaining qualitative data on freight transportation services. But we need to understand the organization around this infrastructure, organization that helps fulfil the exchange of goods.

This paper occupies a crossroads between supply chain management, geographical economics and information systems. Indeed, to respond to this problem, we need to understand why and how the complex networks notion of interaction is effective to elaborate models and simulations leading to an "intelligent" territory management. A first approach of this work appears in [2]. In the following we will discuss logistics and the economic development of territories. Then we present our approach to regional competitiveness through adaptive system of systems (SoS). We consider the economic infrastructure of a region as a global system-of-systems, economic sectors as groups and companies as systems. There are relations of dependencies between enterprises. We hint by economic infrastructure the internal facilities of a territory that ease business activity, such as communication, transportation, distribution networks and markets. We have been inspired by such approach and used a distributed serious game for the prototyping of a territory dynamics.

\section{METHODOLOGICAL APPROACH}

We have two approaches to study the relationship between logistics and the economic development of territories:

- An approach by territories when analysing the infrastructures that are the existing organizations,

- An approach by the interactions between all the supply chain stakeholders, all involved in a search for global territory performance.

The inland logistics is the most complex and the most important part of the whole supply chain. It is complex because supply chains develop in a moving of the spatial scales [4], in a wanted services sophistication (just in time, requirements of distribution networks), in an unstable spatial competition (off shoring and back shoring of firms) and in more complex environmental requirements.

The logistic activity is the physical and organizational continuation of the freight transport as presented by [5]. It materializes by a conurbation on a territory (agglomeration of logistic companies around a hub, idem for the information flows, etc.). The spatial agglomeration of transport and logistics activities is a reality in the harbour area such as those along the Seine axis. We shall thus develop our work on the evolution around the optimization of the logics of spatial setting-up of the logistic and distributive activities. We will analyse some types of products to understand if specificities exist as for the localization criteria of their activities. We shall focus on some types of products to analyse them in order to understand the relation customer-supplier and the impacts on the supply chain. In the Seine axis territory, we will work with manufacturers to analyse their development strategy and their relation between logistics and territory

Thanks to the analysis of the supply chain stakeholders' knowledge on a territory, we supply information to build and study systems of systems. Given the limits of calculation and engineering, the approach by the systems reliability can help to surmount these difficulties.

The architecture of the system-of-systems is modelled as a directed and operational network. The nodes represent either the component systems or a capability that needs to be acquired. Correspondingly, the links represent the dependencies of the operability between the systems or 
between the capabilities. The reliability of a system-of-systems can be evaluated through the estimation of the impact of interoperability barriers in addition to the exchange inefficiency. Further analysis can be executed to assess the benefits of adding or removing systems.

\section{SYSTEM ENGINEERING CONSIDERATIONS}

We will deal with a multidisciplinary approach specifically suited to the context of transport and logistics.

By the very nature of the industry, a multidisciplinary approach that also considers the economic and legal dimensions of this problem is appropriate and fundamental to understand the studied phenomenon. So certain aspects of study require legal and economic reflections, and the integration of contributions from other disciplines (such as management, economy, tax system, competition, etc.) as well as understanding the legal requirements in transport, environment and customs, etc. Hence a multi-disciplinary approach will allow us to integrate several of these variable factors that impact the effective structure of such a complex system as presented in [6].

We can regard the core problem as the complex control of a complex system. The substratum, one region with a measure of autonomy, etc.) is a field where occurs an interconnected web of activities which gives rise to the production of multiple informative exchanges. It is also the place where diverse rules can be applied (economic, legal, etc.).

Diverse participants act within the framework of these rules but for their own needs and with rooms for manoeuvre. We are not studying this as a complex natural system, such as those governed by laws of the physics, and subjected to certain disturbances. In contrast, we consider a frame of reference where the entities have the freedom to act upon their own account and can be in outright conflict with other participants in the system (for resources for example).

To simplify, it operates within this context of a living system that has to remain alive reaching a certain balance. The system is in continual evolution with respect to certain rules that are changeable and hence cannot be easily modelled by a classic model. By being alive, it reacts, readjusts and modifies its hypotheses through auto-adaptation.

By such an approach, we can analyze the mass of information exchanges that we transform into knowledge. By highlighting the cognitive elements at diverse scales, we think we can give a representation of the state of the substratum with intervention onto the controllable elements

\section{SYSTEM OF SYSTEMS APPROACH}

We consider an adaptive system of systems and the problem of multi-scale control. The problem is to realize a real-time control according to global but multi-scale objectives of groups of heterogeneous local reactive systems varying in their behaviours, having possibility of exchange information about theirs states and behaviours to put them in a virtual self-adaptive network managing with coherence their behaviours [7]. The entire system interacting with the real world is presented in (Figure 1).

One way is to work on the reliability is to try to respond to the stimulated concerns related to reliability by assessing the infrastructure of the system-of-systems and its functional dependencies, then to evaluate the interoperability of all dependencies between interconnected systems to finally deduct their reliability. The motivation behind such approach is to inspect the structural architecture of systems-of-systems, especially the dependencies between systems in 
order to evaluate, assess quantify and even anticipate (in some cases) the reliability of the dependencies within systems-of-systems.

Within the hierarchy of systems of systems we focus on an open network of proactive systems: a model with virtualization of the systems mapping the real reactive systems, with on-line control of the behaviours, links, aggregations of activities of groups of systems, management of the emergence of coalitions of actions for the global on-line pseudo-optimization of the activity of the set of proactive systems.

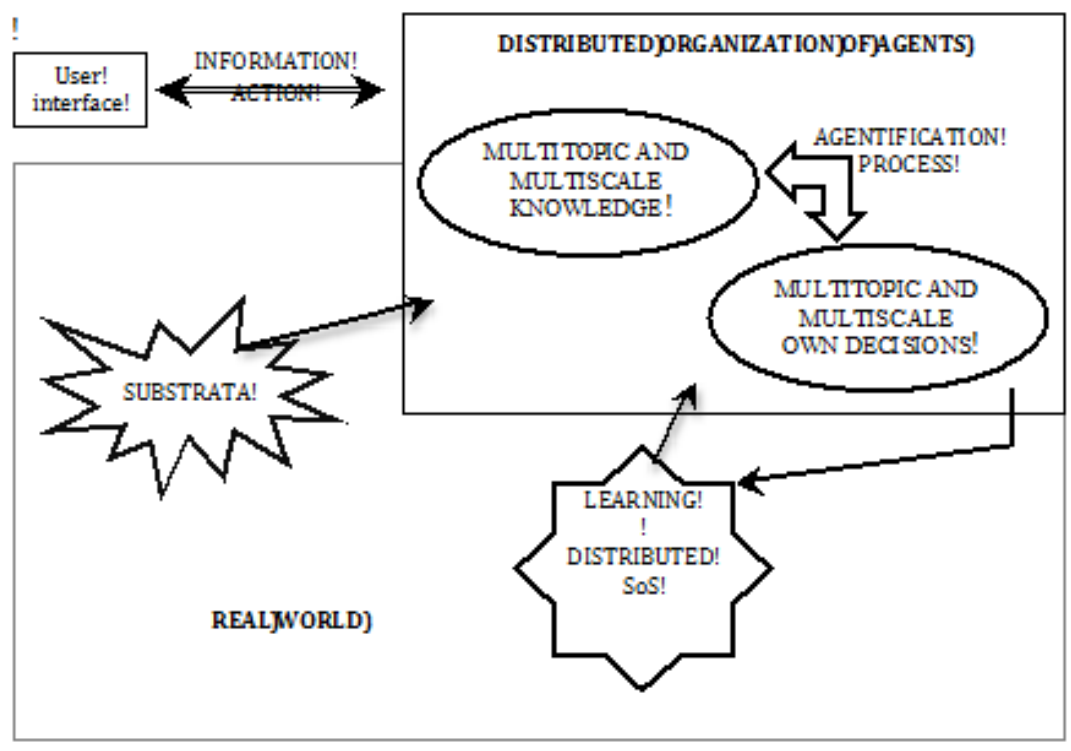

Figure 1. General architecture of the adaptive system

The basis for the construction of such a system is the agentification of the knowledge and the global goals and tendencies that allow the activity of the system in its dynamic environment. An introduction to this approach can be read in [8]. We construct an interpretation layer i.e. the agentification of both knowledge and functionalities. We determine that we know about the problems the sets of functional components have to solve. We also determine what we know about the interaction between the components at all the levels. We must use ontology for the extraction of this knowledge about states, facts and functionalities, as in classical Knowledge Based Problems: see [9]. For that, we can use the statistical analysis about the situations we have to express in the specific domain of application of the system. Then we obtain several hierarchies of knowledge and meta-knowledge with their relations.

From this first structured knowledge, we use an agentification methodology to transform the structural knowledge into a dynamic one using specific aspectual agents. In fact, we extract from knowledge all the pertinent characters of the states and relations between the system's states, and we called them semantic traits. At each semantic trait, we associate several aspectual agents expressing dynamically the pertinence of this semantic trait into the contexts of activity. We thus obtained a massive multi-agent organization of aspectual agents.

More precisely, any information in the functional system has the form of some symbolic data. We first apply a categorization about this information with transformation of information into knowledge as, for example, with the images and statistics we can use. The transformation of the basic information and physical elements behaviours into agents is not a simple one-to-one application, but an interpretation transposing symbolic structures into dynamic structures. For any 
information the object system manipulates, we obtain some semantic traits expressing the characters of the knowledge this information can express in the possible contexts. So, each semantic trait is expressed with several aspectual agents. We can notice that any semantic trait has many aspectual agents matching it: the well-corresponding aspectual agents, the converse agents, the proxy agents and so on, expressing the semantic trait with a cloud made of a dynamic group of aspectual agents around the reified semantic trait.

This aspectual organization will wrap all the basic information of the object layer in order to extract its current characters. By their actions and proactivities, the active aspectual agents will generate the emergence of pertinent groups of semantic traits relative to the current behaviour and actions, taking into account the characters of their contextual relations. Each agent expresses characteristics and partial signification about the situated information contained in the active information, and the meaning of all the current information is expressed with the formation and transformation of groups of coactive aspectual agents. For the generation of this emergent agent's representation we shall use a specific kind of agents' organization management that will be a unified multi-scale control. This is a highlight of how the building work of modelling the Region activities such as an adaptive system of systems begins. The whole building of this system can be read in [1] and [10].

\section{PROTOTYPING}

We distinguished two approaches for the prototyping:

The first one follows the precedent description of a SoS. It needs the development of different tools introduced in the modelling (massive MAS, KBS...) and material (such as the necessary knowledge of the concerned domains). As it has been said in earlier papers, we are still working on this way.

The second approach is to go faster in the prototyping itself. In this way we relax the development constraints and develop a game demonstrator that helps the understanding of the main notions taken into account in the project. Among those notions: autonomy, information exchange and allowed context rules in the different domains are the most important items to take into account.

We went towards this last development direction. Our investigations show an interest in the subject because the work can be taken later in the education area and can be of interest for our students: first as an example of distributed simulation system. Second, as an application that can help in the understanding of the autonomy heart's mechanism. Next, we focus on the distributed simulation example tool.

The building of the tool, as a first prototype, is based on the following rules:

- To use existing simulation environments.

- Each environment should run on one PC.

- To develop on each environment an example (SME, transport company, etc.). Examples follow a business process modelling.

- To use a network supporting the simulation environments in their communication needs. 
Thanks to virtualization technique one can run a first prototype in few machines. Thanks to simulation environments with blocks we can build different examples dealing with logistics, transportation, commerce, etc. that are companies. Briefly, those companies need to exchange with others (information, goods...) with respect of some rules (legal aspects). Companies can grow or decline depending on their activities, management, etc. The companies are autonomous proactive systems.

In the game one person from the group of players takes the role of network-monitor. Others ones represent different stakeholders. Each one is in charge of one company's activities. He/She can follow some overview indicators and can act by delivering "orders" (Figure 2).

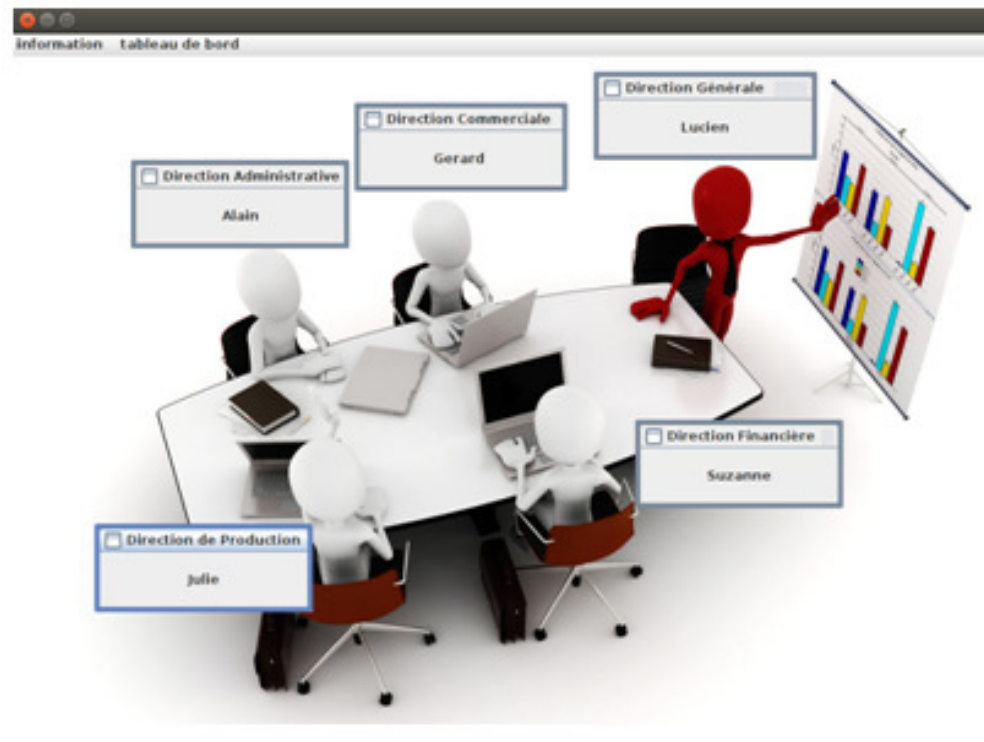

Figure 2. The serious game

The network-monitor is communicating on the global system. He/She is in charge of global rules to be respected. Playing with those rules can modify the state of the eco-system. One objective of the monitor is to maintain or improve the activity of the global system which means to respect some global indicators without loss of balance. That is usually the role of a political decision maker. Then we can observe the different dynamics and particularly the behaviour of the whole system and go towards the study of the reliability of systems-of-systems and its relationship with systems interoperability which is a relatively newly emerging field of research.

\section{CONCLUSIONS}

Thanks to systems of systems approach based on the agentification and knowledge, we plan to represent the interconnected management and decision entities of a Region and give a frame to the competitiveness notion. A serious game can help to better understand the territory dynamics and also to go further in the understanding of systems-of-systems reliability and interoperability, and particularly resilience quantification.

\section{ACKNOWLEDGEMENTS}

This research is supported by the European Union (EU) with the European Regional Development Fund (ERDF) and Normandy Region. 


\section{REFERENCES}

[1] Cardon, A. \& Itmi, M. New Autonomous Systems John Wiley \& Sons, 2016

[2] Verny J., Itmi M., El Hami A., Cardon A., Couturier L. and Abdulrab H., “A Sustainable multidisciplinary Approach to Building Regional Competitiveness". In the Symposium on security and safety of Complex Systems, 2SCS'12. 25-26 May. Agadir, Morocco. 5p. (2012)

[3] Joignaux, G., (2008). "Quel impact logistique sur l'aménagement territorial ?", Notes(Billets) de synthèse du SESP, 168. Pp. 45-50.

[4] Verny, J. and Grigentin, C., (2009). "Container shipping on the Northern Sea Route”, International Journal of Production Economics, 122 (1), 107-117.

[5] Wackermann, G. (dir)., Verny, J. et Al-., (2011). Environnement et écosociété (dictionnaire), Ellipses, Paris.

[6] Axelrod, R. (1997). The complexity of Cooperation: Agent-based Model of Competition and Cooperation. Princeton: University Press.

[7] Keating, C., Rabadi, G., Landaeta, R. E., Bowling, S. (2009). "System of systems engineering for border security and immigration: methodologies, processes and tools". International Journal of System of Systems Engineering (IJSSE), Volume 1 - Issue 4.

[8] Wooldridge, M. and Jennings, N. (1995) "Intelligent Agents: Theory and Practice", Knowledge Ang. Rev., vol. 10, no.2, pp.115-152.

[9] Lenat D. and Guha R., (1990). Building Large Knowledge Based Systems: Representation and Inference in the Cyc Project, Addison-Wesley Publishing.

[10] Itmi, M. and Cardon A. (2012). "Autonomy and Control of Adaptive Systems of Systems", International Journal of Modeling, Simulation and Scientific Computing 3(1): 1240002. 21 pages. World Scientific Publishing Company. DOI: 10.1142/S1793962312400028.

\section{AUTHORS}

Mhamed Itmi earned his PhD in Probability Theory and Statistics in 1980 and second $\mathrm{PhD}$ in Computer Science in 1989. He received his Habilitation Diploma to supervise research (HDR) in 2006 with the focus on the modelling and simulation of distributed discrete event systems. He managed different logistics and transportation research projects and supervised several $\mathrm{PhD}$ theses. He also is the author and co-author of more than 100 papers published in international journals, conferences and books. His research presently focuses on autonomous systems. He is an Associate Professor at the INSA-Rouen, France.

Abdelkhalak El Hami is a Full Professor at INSA Rouen, Normandy France, as well as Deputy Director of LMN and director of mechanical engineers. He's research activities include reliability-optimization systems. He has supervised $38 \mathrm{PhD}$ theses. $\mathrm{He}$ also is the author and co-author of more than a twenty books and more than 550 papers published in international journals and conferences. He has a doctorate in engineering sciences from the University of Franche-Comté in France (1992). He received his Habilitation diploma to supervise research (HDR) in 2000. He's Editor in

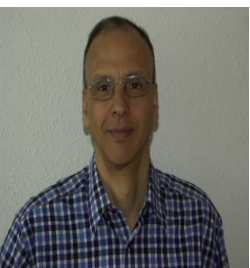
chef of 3 Set of international Book, ISTE, Wiley and Elsivier. 